\title{
Effects in Sheep of Hypoxia on Levels of Lactate, Pyruvate, and Glucose in Blood of Mothers and Fetus
}

\author{
L.I. MANN ${ }^{[18]}$ \\ National Institutes of Health, National Institute of Child Health \\ and Human Development, Behavioral Biology Branch, Bethesda, Maryland, USA
}

\begin{abstract}
Extract
In nine experiments with sheep, effects of hypoxia on levels of lactate, pyruvate, and glucose in maternal and fetal blood were studied. Blood samples were obtained simultaneously from the four uterine and umbilical vessels prior to, during, and following an episode of severe hypoxia.

The concentration of lactate, pyruvate, and hydrogen ions, and the $\mathrm{CO}_{2}$ tension was greater in the umbilical circulation than in the uterine circulation during the period prior to hypoxia. There was no apparent exchange of lactate or pyruvate across the placenta in either direction at this time. The concentration of glucose in the umbilical vein, however, was directly related to that of the uterine vein.

When progressively mild-to-severe hypoxia occurred in the fetus and placenta, first pyruvate, then lactate, accumulated within the umbilical circulation. The venous-arterial (V-A) difference of lactate in the uterine and umbilical vessels, as well as total uterine and fetal excess lactate production, increased significantly during the final $10 \%$ interval of the period of hypoxia. The concentration of lactate in the uterine vein blood was directly related to the concentration of lactate in the umbilical vein during this final period. The decrease in the concentration of glucose in the uterine vein blood was greater than the decrease in the umbilical vein blood.

The metabolism of lactate proceeded slowly after relief from hypoxia. Though the concentration of lactate was still elevated approximately $30 \mathrm{~min}$ into recovery, the V-A and maternal-fetal concentration differences were similar to prehypoxic values.
\end{abstract}

\section{Speculation}

The placenta regulates the metabolic response of the fetus to hypoxia by providing a pathway whereby excess lactate produced by the fetus can be eliminated. The mechanism by which this is accomplished might involve a change in the electrochemical gradient across the membrane, anatomical changes within the membrane, or alterations of enzyme pathways at the placental site.

\section{Introduction}

The role of the placenta in the regulation of fetal metabolism and acid-base homeostasis has not been described because of difficulty in obtaining simultaneous blood samples from both maternal and fetal placental vessels. The introduction of a technique [10] in which these vessels are catheterized while the fetus remains undisturbed in utero makes possible experiments to assess this function. In this paper, an analysis of meta- 
bolic observations made prior to, during, and following hypoxia is presented.

\section{Materials and Methods}

Twenty-eight experiments were performed on Columbian ewes with dated gestations. The experiments were designed to study the temporal and functional interrelation of cardiovascular, metabolic, and acid-base changes in the fetus during various levels of hypoxia in the mother (ewe breathing 15,7.5, or $0 \% \mathrm{O}_{2}$ ); correlations with alterations in the fetal EEG were also attempted. The end point of the hypoxic period was the onset of the isoelectric stage of the EEG. The physiological analysis of these observations has been reported [9].

Of the 28 experiments, 9 fulfilled the criteria established for inclusion in this study. The criteria were: 1) simultaneous blood samples (obtained successfully from each of the four placental vessels prior to hypoxia, during the final $10 \%$ interval of the period of hypoxia, and approximately $30 \mathrm{~min}$ into recovery; additional samples were occasionally obtained at other periods during hypoxia and recovery) ; 2) survival of the fetus during the period of hypoxia and a live delivery $60 \mathrm{~min}$ or more into recovery; and 3) induction of fetal hypoxia by breathing the ewe with $7.5 \% \mathrm{O}_{2}$. The total period of hypoxia ranged from 6.5 to 20.5 min (mean: $13.3 \pm 1.5 \mathrm{~min} \mathrm{SEM})$. In all experiments, the last $10 \%$ period of hypoxia was characterized by fetal bradycardia and either an abnormal or isoelectric EEG [9].

Anesthesia was induced and maintained with Fluothane, $0.6-1.2 \%$ and $98 \% \mathrm{O}_{2}$ during the control and recovery periods; the anesthetic was delivered through a tracheostomy by use of a respirator and anesthetic apparatus. Polyethylene catheters were placed into the maternal aorta (MA) from the femoral artery, into the main uterine vein (MV) through a tributary in the broad ligament, and into the main umbilical artery (UA) and vein (UV) in the cord through tributaries in the chorioallantoic membrane. The fetus remained in utero throughout the experiment.

Two milliliters of each heparinized blood sample were deproteinated within $1 \mathrm{~min}$ of sampling by the addition of $2 \mathrm{ml}$ of cold $10 \%$ perchloric acid. Supernatant concentrations of glucose, lactate, and pyruvate were then determined by enzymatic methods [14]. Lactate and pyruvate were determined from the spectrophotometric difference of the oxidation-reduction of nicotinamide adenine dinucleotide (NAD) in the presence of excess lactic dehydrogenase.

Using a $\mathrm{pH}$ and gas analyzer [15], determinations of $\mathrm{pH}, \mathrm{pCO}_{2}$, and $\mathrm{pO}_{2}$ were performed within $1 \mathrm{~h}$ of sampling on a 1-ml blood sample kept in ice until used.
Venous-arterial differences were determined for both the uterine and umbilical circulations. Because umbilical artery blood is venous blood, the umbilical venous-arterial difference ( $\mathrm{V}-\mathrm{A})$ was calculated from the equation:

$$
\Delta \mathrm{F}=\mathrm{UA}-\mathrm{UV}
$$

(UA $=$ umbilical artery - UV $=$ umbilical vein). Negative values reflected loss on circulation through the fetus or gain on circulation through the placenta. The uterine V-A difference was calculated from the equation:

$$
\triangle \mathrm{M}=\mathrm{MV}-\mathrm{MA}
$$

$(\mathrm{MV}=$ uterine vein $-\mathrm{MA}=$ uterine artery $)$. The uterine vein sample included blood that drained from the multicotyledonary placenta as well as the endometrium and myometrium, so that the uterine difference represented total uterine metabolism. Differences in maternal-fetal concentration were determined from the equation:

$$
\Delta \mathrm{M}-\mathrm{F}=\mathrm{MV}-\mathrm{UV}
$$

so that negative values reflect a greater fetal than maternal concentration.

Excess lactate, the increased amount of lactate that occurs in excess of an increase of pyruvate, was calculated by considering arterial and venous concentrations of lactate and pyruvate at the same time ( $\Delta \mathrm{XL})$.

$$
\Delta \mathrm{XL}=(\mathrm{Lv}-\mathrm{La})-(\mathrm{Pv}-\mathrm{Pa})\left(\frac{\mathrm{La}}{\mathrm{Pa}}\right) \quad \text { (Equation 1) }
$$

where: $\mathrm{Lv}, \mathrm{Pv}=$ lactate, pyruvate concentrations in venous blood, i.e., UA or MV; and

$\mathrm{La}, \mathrm{Pa}=$ lactate, pyruvate concentrations in arterial blood, i. e., UV or MA

This equation has been derived and discussed by Huckabee [5].

The significance of a difference in concentration or gradient from one time to another was assessed by paired analyses (Student's $t$ test) and is expressed in terms of probability $(P)$ values.

\section{Results}

The results obtained during base line conditions, hypoxia, and recovery for each experiment are shown in table I. The course of events in a single experiment (ewe 24, table I) is presented in figure 1 .

\section{Oxygen}

The oxygen tension in the maternal artery was variable during the base-line period (range: 52-300 $\mathrm{mm} \mathrm{Hg}$ ). This variability was probably due to the difficulty in maintaining an adequate pulmonary ven- 
tilation-perfusion ratio in this species when in the supine position, even though positive pressure $\mathrm{O}_{2}$ was given. The mean oxygen tension in the uterine vein was fixed at $53.7 \pm 5.7 \mathrm{~mm} \mathrm{Hg}$ (table I). The mean oxygen tension in the umbilical vein was $29.0 \pm 2.6 \mathrm{~mm}$ $\mathrm{Hg}$. These figures are similar to those reported by others using a chronic preparation [10]. The direct relation between the oxygen tension in the uterine (MV) and umbilical veins (UV) at the time of sampling is shown in figures 1 and $2 A$. The $\Delta \mathrm{F}, \Delta \mathrm{M}$, and $\triangle \mathrm{M}-\mathrm{F}$ narrowed as the oxygen tension decreased in the maternal circulation. The oxygen tension in UV was $6 \mathrm{~mm} \mathrm{Hg}$ at $11 \mathrm{~min}$ of hypoxia in experiment 24 (fig. 1) and decreased only $1 \mathrm{~mm} \mathrm{Hg}$ during the next 8.5

Fig. 1. Simultaneous observations from the four placental vessels at intervals during hypoxia and recovery in experiment 24 (table I). • : maternal artery (MA). $O$ : uterine vein (MV). A: umbilical vein (UV). $\triangle$ : umbilical artery (UA).

Fig. 2. Correlation between oxygen tension $(A)$, carbon dioxide tension $(B)$, glucose $(C)$ and lactate $(D)$ in the uterine vein (MV) and umbilical vein (UV) at the time of sampling prior to hypoxia $\bullet$; during the final $10 \%$ interval of the period of hypoxia $\triangle$; and during recovery from hypoxia $\circ$ in nine experiments with sheep.
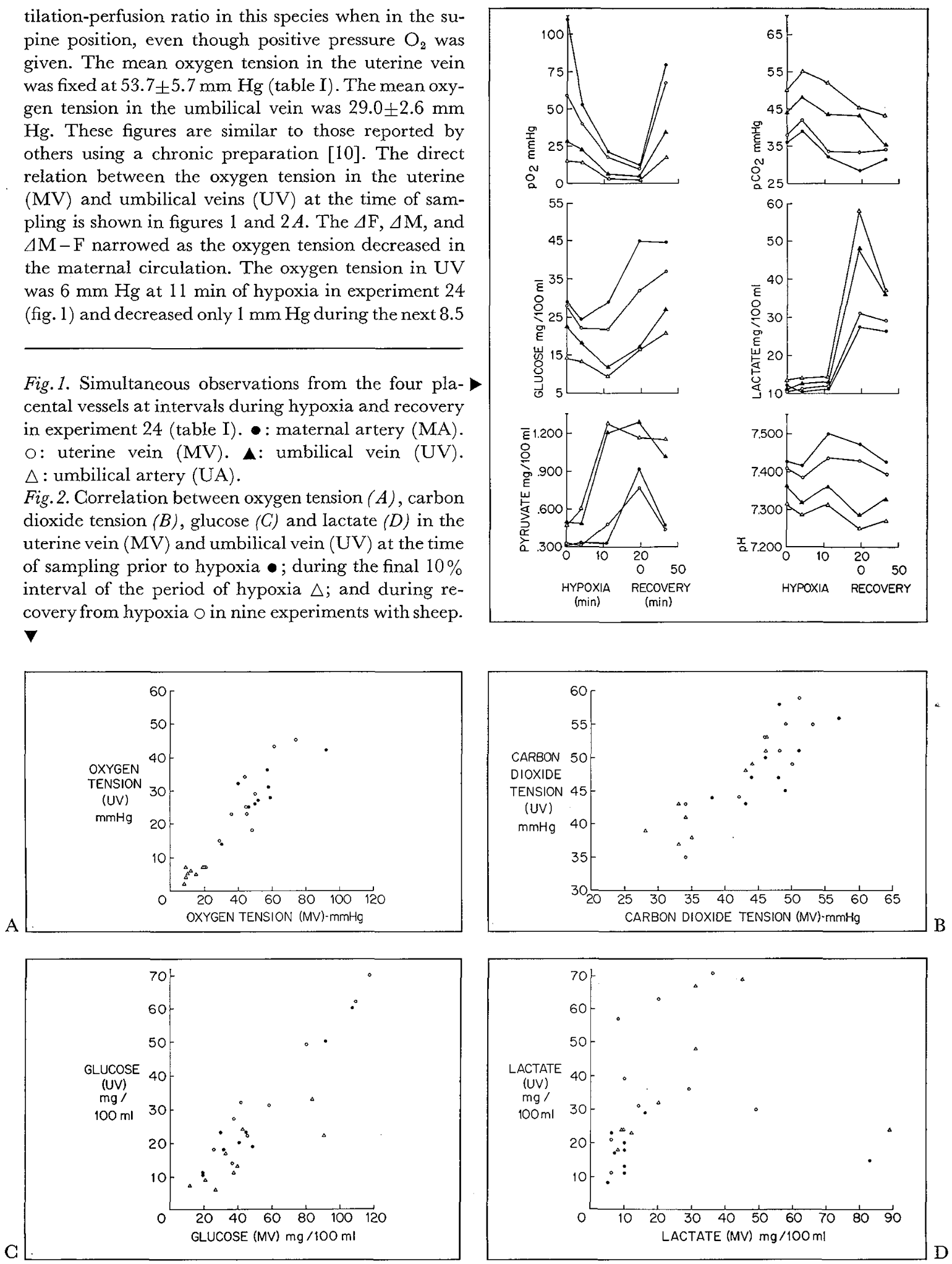
min; the oxygen tension in $\mathrm{MV}$ decreased $8 \mathrm{~mm} \mathrm{Hg}$ in the same 8.5 -min period. In the nine experiments, the mean oxygen tension in UV during the final $10 \%$ interval of hypoxia was $5.6 \pm 0.6 \mathrm{~mm} \mathrm{Hg}$. Oxygen saturation of whole blood in the fetus, calculated from the equation presented by Meschia et al. [11], was below $10 \%$. Mean oxygen tension in the uterine vein at this time was $14 \pm 1.9 \mathrm{~mm} \mathrm{Hg}$ (saturation about $15 \%$ ). Oxygen tension in the uterine and umbilical circulation returned rapidly to base-line values within 1 min following reintroduction of oxygen. Oxygen tension in $\mathrm{MV}$ and $\mathrm{UV}$, and their relation approximately $30 \mathrm{~min}$ in recovery (range: $22-45 \mathrm{~min}$ ), were similar to base-line values.

\section{Carbon Dioxide}

Hypocapnia in the mother occurred as a result of hyperventilation during the final 10\%-interval of the hypoxic period. The decrease in $\mathrm{pCO}_{2}$ in $\mathrm{MV}$ (table I) was not proportional to the decrease in the maternal aorta, so that the uterine V-A difference widened (table I, fig. 1) in seven of the nine experiments. The decrease of $\mathrm{pCO}_{2}$ in $\mathrm{UV}$ was less than the decrease in MV (table I, figs. 1 and $2 B$ ), and increased in one experiment (ewe 14). As a result of more variable values of $\mathrm{pCO}_{2}$ in $\mathrm{UA}$, the $\mathrm{V}$-A difference in the umbilical vessels was variable, decreasing in five experiments and increasing in four. The umbilical V-A difference widened during the first $11 \mathrm{~min}$ of hypoxia in experiment 24 (fig. 1), but then narrowed considerably after $19.5 \mathrm{~min}$ of hypoxia. The V-A differences were variable during recovery but generally approaching base-line values.

\section{Glucose}

The ratio of glucose concentration in MV and UV approximated 1.8 during base line and recovery periods (fig. $2 \mathrm{C}$ ). The concentration of glucose in UV decreased in eight experiments during the $10 \%$ of hypoxia, and decreased in MV in six experiments. Further, the decrease of glucose concentration in UV was greater than the decrease in MV in six of the nine experiments (fig. 1, table I), so that $\triangle \mathrm{M}-\mathrm{F}$ increased. The V-A difference in the fetus narrowed significantly $(P<0.01)$ as the concentration of glucose in UA decreased less than the concentration in UV, and actually increased significantly $(P<0.01)$ in all nine experiments during late hypoxia. The course of these events is seen clearly in figure 1.

The concentration of glucose was greater than base line in MV, in eight of the nine experiments; in UV, the concentration was greater than base line in all nine experiments during recovery. The V-A differences in the uterine and umbilical vessels were variable, but generally returning toward base-line values.

\section{Lactate and Pyruvate}

The concentration of lactate and pyruvate was higher in UV than in MV in eight experiments prior to hypoxia (fig. $2 D$ ).

Ewe 30 was anesthetized with Fluothane after initial spinal anesthesia failed. The elevation of lactate in $\mathrm{MV}$ $(83 \mathrm{mg} / 100 \mathrm{ml})$, which probably resulted from struggling during restraint under spinal anesthesia, was not associated with a proportionate rise in lactate in $\mathrm{UV}$ $(15 \mathrm{mg} / 100 \mathrm{ml})$.

The V-A differences in uterine and umbilical vessels $(\Delta \mathrm{M}, \Delta \mathrm{F}$ [table I]) were variable during the base-line period. In lactate concentration, negative umbilical V-A differences were evident in five experiments while positive differences were observed in four experiments. Venous-arterial differences in pyruvate concentration in umbilical vessels were less variable. A positive $\mathrm{V}-\mathrm{A}$ difference was observed in seven of the experiments and a negative difference in two. In one of the two experiments (ewe 24, fig. 1), a negative pyruvate $\mathrm{V}$-A difference was associated with a positive lactate $V$-A difference. This experiment was the only one in which excess lactate was produced by the fetus prior to hypoxia (ewe $24,+2.3 \mathrm{mg} / 100 \mathrm{ml}$; table I, fig. 1).

Venous-arterial differences in lactate concentration observed in uterine vessels were similarly variable during the base-line period. A negative $\mathrm{V}$-A difference was observed in five experiments; positive V-A differences in pyruvate concentration occurred in all nine experiments. Excess lactate production by the total uterine mass was evident in only one experiment (ewe 30).

The effect of hypoxia on maternal and fetal metabolism of lactate and pyruvate can be seen in figure 1 (exp.24, table I). The V-A difference of pyruvate in umbilical vessels was positive after $4 \mathrm{~min}$ of hypoxia because of increased concentration of pyruvate in UA. The V-A difference of lactate narrowed, due to a slightly greater increase in the concentration of lactate in UV than in UA. It would appear that lactate was oxidized to pyruvate by the fetus while pyruvate was reduced to lactate by the placenta. The concentration of pyruvate decreased and the concentration of lactate increased in $\mathrm{MV}$, whereas concentration gradients of pyruvate increased and those of lactate decreased in MA. The V-A difference of pyruvate and lactate in uterine vessels was the reverse of those pertaining during base-line observations.

A marked increase in the concentration of pyruvate was observed in UA and UV at 11.5 min of hypoxia. The concentration of pyruvate in MV increased and the uterine pyruvate $\mathrm{V}$-A difference widened at this time. The concentration of lactate and the uterine and umbilical lactate V-A differences were essentially similar to those found during the 4-min observations. 
Table I. Metabolic and acid-base observations prior to hypoxia, during the last $10 \%$ interval of the period of hypoxia, and during recovery from hypoxia in nine experiments with sheep

\begin{tabular}{|c|c|c|c|c|c|c|c|c|c|c|c|c|c|c|}
\hline \multirow{2}{*}{$\begin{array}{l}\text { Ewe } \\
\text { no. }\end{array}$} & \multirow{2}{*}{$\begin{array}{c}\text { Gestation } \\
\text { age of fetus, } \\
\text { days }\end{array}$} & \multirow{2}{*}{$\begin{array}{l}\text { Wt of } \\
\text { fetus, } \\
\mathrm{g}\end{array}$} & \multicolumn{4}{|c|}{$\mathrm{pO}_{2}, \mathrm{~mm} \mathrm{Hg}$} & \multicolumn{4}{|c|}{$\mathrm{pCO}_{2}, \mathrm{~mm} \mathrm{Hg}$} & \multicolumn{4}{|c|}{$\mathrm{pH}$} \\
\hline & & & MV & $\Delta \mathrm{M}^{2}$ & UV & $\Delta \mathrm{F}$ & MV & $\Delta \mathrm{M}$ & UV & $\Delta \mathrm{F}$ & MV & $\Delta \mathrm{M}$ & UV & $\Delta \mathrm{F}$ \\
\hline \multirow[t]{3}{*}{$29-S^{1}$} & 110 & 1,814 & 58 & -52 & 31 & -15 & 48 & 3 & 58 & 6 & 7.368 & -0.020 & 7.246 & -0.041 \\
\hline & & & 9 & -4 & 7 & -3 & 28 & 7 & 39 & 12 & 7.500 & -0.050 & 7.284 & -0.096 \\
\hline & & & 45 & -39 & 25 & -8 & 51 & 11 & 59 & 4 & 7.297 & -0.048 & 7.148 & -0.015 \\
\hline \multirow[t]{3}{*}{$24-\mathrm{S}$} & 120 & 3,175 & 59 & -61 & 28 & -13 & 38 & 2 & 44 & 6 & 7.408 & -0.017 & 7.362 & -0.052 \\
\hline & & & 10 & -3 & 5 & -3 & 33 & 5 & 43 & 2 & 7.428 & -0.044 & 7.285 & -0.035 \\
\hline & & & 44 & -32 & 34 & -17 & 34 & 3 & 35 & 8 & 7.392 & -0.033 & 7.325 & -0.057 \\
\hline \multirow[t]{3}{*}{$14-\mathrm{S}$} & 125 & 3,856 & 45 & -24 & 25 & -11 & 43 & 1 & 43 & 5 & 7.358 & -0.036 & 7.285 & -0.027 \\
\hline & & & 12 & -4 & 6 & -2 & 42 & 7 & 48 & 1 & 7.314 & -0.084 & 7.246 & -0.017 \\
\hline & & & 50 & -16 & 29 & -12 & 42 & 9 & 44 & 4 & 7.368 & -0.035 & 7.283 & -0.022 \\
\hline \multirow[t]{3}{*}{$28-\mathrm{S}$} & 127 & 3,856 & 57 & -244 & 36 & -16 & 48 & 8 & 47 & 8 & 7.332 & -0.025 & 7.182 & -0.050 \\
\hline & & & 15 & -4 & 5 & -3 & 33 & 12 & 37 & 9 & 7.380 & -0.060 & 7.160 & -0.042 \\
\hline & & & 61 & -199 & 43 & -19 & 53 & 13 & 55 & 13 & 7.288 & -0.047 & 7.052 & -0.022 \\
\hline \multirow[t]{3}{*}{$20-T$} & 132 & 3,629 & 40 & -116 & 32 & -16 & 57 & 2 & 56 & 9 & 7.275 & -0.070 & 7.232 & -0.030 \\
\hline & & & 20 & -5 & 7 & -3 & 46 & 5 & 53 & 5 & 7.372 & -0.058 & 7.272 & -0.037 \\
\hline & & & 36 & -86 & 23 & -8 & 46 & 6 & 53 & 5 & 7.310 & -0.048 & 7.210 & -0.025 \\
\hline \multirow[t]{3}{*}{$30-\mathrm{S}$} & 132 & 4,082 & 92 & -148 & 42 & -21 & 46 & 2 & 50 & 7 & 7.145 & -0.013 & 7.262 & -0.030 \\
\hline & & & 8 & -6 & 2 & -0.5 & 44 & 13 & 49 & 6 & 7.182 & -0.073 & 7.268 & -0.052 \\
\hline & & & 74 & -54 & 45 & -24 & 48 & 6 & 51 & 7 & 7.170 & -0.028 & 7.275 & -0.065 \\
\hline \multirow[t]{3}{*}{$33-\mathrm{T}$} & 135 & 4,309 & 30 & -22 & 14 & -5 & 44 & 7 & 47 & 7 & 7.335 & -0.030 & 7.192 & -0.027 \\
\hline & & & 21 & -5 & 7 & -2 & 34 & 6 & 41 & 9 & 7.395 & -0.070 & 7.208 & -0.041 \\
\hline & & & 29 & -22 & 15 & -5 & 34 & 5 & 43 & 8 & 7.300 & -0.012 & 7.125 & -0.040 \\
\hline \multirow[t]{3}{*}{$34-S$} & 136 & 5,330 & 52 & -208 & 27 & -10 & 49 & 3 & 45 & 13 & 7.315 & -0.050 & 7.226 & -0.024 \\
\hline & & & 9 & -10 & 4 & -1 & 35 & 12 & 38 & 10 & 7.388 & -0.157 & 7.262 & -0.052 \\
\hline & & & 48 & -212 & 18 & -3 & 50 & 4 & 49 & 8 & 7.305 & -0.032 & 7.138 & -0.028 \\
\hline \multirow[t]{9}{*}{$17-S$} & 137 & 5,500 & 50 & -26 & 26 & -11 & 51 & 13 & 51 & 4 & 7.384 & -0.011 & 7.302 & -0.027 \\
\hline & & & 22 & -2 & 7 & -3 & 46 & 5 & 51 & 8 & 7.385 & -0.065 & 7.307 & -0.065 \\
\hline & & & 45 & -46 & 23 & -9 & 49 & 1 & 55 & 6 & 7.350 & -0.045 & 7.245 & -0.043 \\
\hline & Base line $e^{4}$ & & 53.7 & -100.0 & 29.0 & -13.1 & 47.1 & 4.6 & 49.0 & 7.2 & 7.324 & -0.030 & 7.254 & -0.034 \\
\hline & & & \pm 5.7 & \pm 27.9 & \pm 2.6 & \pm 1.5 & \pm 1.8 & \pm 1.3 & \pm 1.7 & \pm 0.9 & \pm 0.026 & \pm 0.006 & \pm 0.019 & \pm 0.004 \\
\hline & Hypoxia & & 14.0 & -4.8 & 5.6 & -2.3 & 38.0 & 8.0 & 44.3 & 6.9 & 7.372 & -0.073 & 7.255 & -0.049 \\
\hline & & & \pm 1.9 & \pm 0.8 & \pm 0.6 & \pm 0.3 & \pm 2.2 & \pm 1.1 & \pm 2.0 & \pm 1.2 & \pm 0.029 & \pm 0.011 & \pm 0.015 & \pm 0.007 \\
\hline & Recovery & & 48.0 & -78.4 & 28.3 & -11.7 & 45.2 & 6.4 & 49.3 & 7.0 & 7.309 & -0.036 & 7.200 & -0.035 \\
\hline & & & \pm 4.4 & \pm 24.9 & \pm 3.5 & \pm 2.3 & \pm 2.4 & \pm 1.3 & \pm 2.5 & \pm 0.9 & \pm 0.021 & \pm 0.004 & \pm 0.030 & \pm 0.006 \\
\hline
\end{tabular}


Table I. (Continued)

\begin{tabular}{|c|c|c|c|c|c|c|c|c|c|c|c|c|c|c|c|c|}
\hline \multirow[t]{2}{*}{$\begin{array}{l}\text { Ewe } \\
\text { no. }\end{array}$} & \multirow{2}{*}{$\begin{array}{l}\text { Gesta- } \\
\text { tion age } \\
\text { of fetus, } \\
\text { days }\end{array}$} & \multirow{2}{*}{$\begin{array}{l}\text { Wt of } \\
\text { fetus, } \\
g\end{array}$} & \multicolumn{4}{|c|}{ Glucose, $\mathrm{mg} / 100 \mathrm{ml}$} & \multicolumn{4}{|c|}{ Pyruvate, $\mathrm{mg} / 100 \mathrm{ml}$} & \multicolumn{4}{|c|}{ Lactate, $\mathrm{mg} / 100 \mathrm{ml}$} & \multicolumn{2}{|c|}{$\begin{array}{c}\text { Excess lactate } \\
\mathrm{mg} / 100 \mathrm{ml}\end{array}$} \\
\hline & & & MV & $\Delta \mathrm{M}$ & UV & $\Delta \mathrm{F}$ & MV & $\Delta \mathrm{M}$ & UV & $\Delta \mathrm{F}$ & MV & $\Delta \mathrm{M}$ & UV & $\Delta \mathrm{F}$ & Fetal & $\mathrm{T} U \mathrm{~T}^{3}$ \\
\hline \multirow[t]{3}{*}{$29-S^{1}$} & 110 & 1,814 & 44 & -4 & 23 & -9 & 0.69 & 0.08 & 0.70 & 0.08 & 10 & -1.10 & 18 & 1.76 & -0.4 & -2.5 \\
\hline & & & 39 & -14 & 13 & -4 & 1.28 & 0.09 & 1.07 & 0.06 & 45 & 8.90 & 69 & 19.30 & 15.7 & 6.2 \\
\hline & & & 80 & -2 & 49 & -6 & 0.64 & 0.16 & 0.79 & 0.41 & 36 & 8.40 & 71 & 8.20 & -28.1 & -0.5 \\
\hline \multirow[t]{3}{*}{$24-\mathrm{S}$} & 120 & 3,175 & 29 & -1 & 23 & -8 & 0.32 & 0.03 & 0.50 & -0.01 & 10 & -1.69 & 11 & 2.10 & 2.3 & -2.8 \\
\hline & & & 32 & -13 & 17 & 0 & 0.77 & -0.16 & 1.29 & -0.12 & 31 & 3.90 & 48 & 10.40 & 15.0 & 8.6 \\
\hline & & & 37 & -7 & 27 & -6 & 0.45 & -0.03 & 1.04 & 0.12 & 29 & 3.10 & 36 & 1.20 & -3.1 & 4.7 \\
\hline \multirow[t]{3}{*}{$14-S$} & 125 & 3,856 & 31 & -10 & 18 & -11 & 0.38 & 0.05 & 0.46 & 0.37 & 10 & 0.60 & 20 & -2.40 & -18.5 & -0.8 \\
\hline & & & 26 & -12 & 6 & -5 & 0.52 & 0.11 & 1.19 & -0.05 & 12 & 2.10 & 23 & 0.30 & 1.3 & 4.2 \\
\hline & & & 41 & -11 & 32 & -12 & 0.41 & 0.01 & 0.61 & 0.52 & 14 & 0.50 & 31 & 0.20 & -25.9 & 0.1 \\
\hline \multirow[t]{3}{*}{ 28-S } & 127 & 3,856 & 107 & -5 & 60 & -13 & 0.40 & 0.00 & 0.42 & 0.10 & 10 & 5.83 & 13 & -4.91 & -7.8 & -1.7 \\
\hline & & & 90 & -8 & 22 & -1 & 0.80 & 0.03 & 0.67 & 0.19 & 20 & 8.60 & 32 & 2.00 & 0.9 & 0.4 \\
\hline & & & 109 & -4 & 62 & -5 & 0.41 & -0.014 & 0.67 & 0.14 & 8 & 0.31 & 57 & -8.40 & -20.8 & 0.5 \\
\hline \multirow[t]{3}{*}{$20-\mathrm{T}$} & 132 & 3,629 & 48 & -4 & 19 & -10 & 0.31 & 0.02 & 0.53 & -0.10 & 5 & -0.30 & 8 & -3.30 & -1.7 & -0.7 \\
\hline & & & 37 & -11 & 11 & -3 & 0.55 & 0.18 & 0.55 & 0.30 & 8 & 1.46 & 18 & 1.21 & 0.8 & 1.2 \\
\hline & & & 45 & -29 & 22 & -2 & 0.73 & 0.16 & 0.54 & 0.45 & 6 & -2.99 & 11 & 1.34 & -8.2 & -5.4 \\
\hline \multirow[t]{3}{*}{$30-S$} & 132 & 4,082 & 91 & -6 & 50 & -14 & 1.28 & 0.06 & 0.60 & 0.12 & 83 & 5.90 & 15 & -3.90 & -6.9 & 2.5 \\
\hline & & & 83 & -7 & 33 & -3 & 1.76 & 0.13 & 0.73 & 0.14 & 89 & 12.10 & 24 & 4.60 & 0.1 & 17.4 \\
\hline & & & 117 & -5 & 70 & -8 & 0.58 & 0.03 & 0.49 & 0.16 & 49 & 1.80 & 30 & -7.10 & -16.8 & -1.1 \\
\hline \multirow[t]{3}{*}{$33-\mathrm{T}$} & 135 & 4,309 & 19 & -6 & 11 & -6 & 0.61 & 0.17 & 1.05 & 0.72 & 7 & 0.97 & 17 & 0.96 & -10.8 & -1.6 \\
\hline & & & 20 & -12 & 9 & -5 & 0.63 & 0.25 & 0.98 & 0.73 & 9 & 2.36 & 24 & 7.40 & 2.2 & 3.3 \\
\hline & & & 36 & -6 & 14 & -3 & 0.39 & 0.07 & 1.02 & 0.66 & 6 & 2.55 & 21 & 2.10 & -11.8 & 1.8 \\
\hline \multirow[t]{3}{*}{ 34-S } & 136 & 5,330 & 40 & -10 & 20 & -3 & 1.05 & 0.01 & 1.08 & 0.34 & 16 & -0.75 & 29 & -0.80 & -9.9 & -0.8 \\
\hline & & & 42 & -31 & 24 & -5 & 1.45 & 0.09 & 0.92 & 0.22 & 31 & 2.00 & 67 & 1.60 & 1.2 & 0.1 \\
\hline & & & 58 & -38 & 31 & -8 & 0.98 & 0.30 & 1.30 & 0.58 & 20 & -0.50 & 63 & 5.50 & -22.6 & -9.8 \\
\hline \multirow[t]{9}{*}{ 17-S } & 137 & 5,500 & 19 & -2 & 11 & -6 & 0.34 & 0.03 & 0.63 & 0.19 & 6 & -4.41 & 23 & 3.10 & -3.6 & -5.3 \\
\hline & & & II & -10 & 7 & -1 & 0.56 & 0.01 & 1.39 & -0.24 & 9 & 1.43 & 24 & 3.30 & 6.3 & 1.3 \\
\hline & & & 25 & -3 & 18 & -1 & 0.34 & -0.01 & 0.85 & 0.25 & 10 & 2.15 & 39 & -8.80 & -20.3 & 2.3 \\
\hline & Base line $e^{4}$ & & 47.6 & -5.3 & 26.1 & -8.9 & 0.60 & 0.05 & 0.66 & 0.20 & 17.4 & 0.56 & 17.1 & -0.82 & -6.4 & -1.5 \\
\hline & & & \pm 10.4 & \pm 1.0 & \pm 5.7 & \pm 1.2 & \pm 0.12 & \pm 0.02 & \pm 0.08 & \pm 0.08 & \pm 8.3 & \pm 1.13 & \pm 2.1 & \pm 0.98 & \pm 2.1 & \pm 0.7 \\
\hline & Hypoxia & & 42.2 & -13.1 & 15.8 & -3.0 & 0.92 & 0.08 & 0.98 & 0.14 & 28.2 & 4.80 & 36.0 & 5.50 & +4.8 & +4.7 \\
\hline & & & \pm 8.9 & \pm 2.4 & \pm 3.0 & \pm 0.6 & \pm 0.15 & \pm 0.04 & \pm 0.09 & \pm 0.09 & \pm 8.7 & \pm 1.30 & \pm 6.7 & \pm 2.00 & \pm 2.1 & \pm 1.8 \\
\hline & Recovery & & 60.9 & -11.7 & 36.1 & -5.7 & 0.55 & 0.08 & 0.81 & 0.37 & 19.9 & 1.70 & 39.9 & -0.64 & -17.5 & -0.82 \\
\hline & & & \pm 11.2 & \pm 4.3 & \pm 6.6 & \pm 1.1 & \pm 0.07 & \pm 0.03 & \pm 0.09 & \pm 0.07 & \pm 5.1 & \pm 1.04 & \pm 6.6 & \pm 2.04 & \pm 2.8 & \pm 1.5 \\
\hline
\end{tabular}

${ }^{1} \mathrm{~S}$, single fetus; $\mathrm{T}$, twins. $\quad{ }^{2}$ See text for calculation of uterine $(\Delta \mathrm{M})$ and umbilical $(\Delta \mathrm{F})$ gradients. UV $=$ umbilical vein; ${ }^{3} \mathrm{~T}$ UT, total uterus. ${ }^{4}$ Mean \pm SEM. 
The events at 19.5 min hypoxia were associated with severe hypoxia in the fetus and placenta. The increase in lactate concentration in UA was greater than that in UV, while the concentration of pyruvate rose in UV and fell in UA. The V-A difference in lactate in umbilical vessels increased markedly from $2.10 \mathrm{mg} /$ $100 \mathrm{ml}$ during base line to $10.4 \mathrm{mg} / 100 \mathrm{ml}$ at this point. Excess lactate increased from $+2.3 \mathrm{mg} / 100 \mathrm{ml}$ to $+15.0 \mathrm{mg} / 100 \mathrm{ml}$. Similarly, the V-A difference of lactate in the mother increased from $-1.69 \mathrm{mg} / 100 \mathrm{ml}$ to $+3.9 \mathrm{mg} / 100 \mathrm{ml}$, while excess lactate increased from $-2.8 \mathrm{mg} / 100 \mathrm{mI}$ to $+8.6 \mathrm{mg} / 100 \mathrm{mI}$. The concentration of lactate in $\mathrm{MV}$, plotted as a function of the concentration in UV for the nine experiments (fig. $2 D$ ), showed a more direct relation during hypoxia than during base-line or recovery.

The V-A differences of lactate and excess lactate in uterine and umbilical vessels increased in each experiment during the final $10 \%$ interval of the period of hypoxia. The increase in the lactate $\mathrm{V}$-A differences was highly significant $(P<0.01)$.

The concentration of lactate in all four vessels remained elevated during recovery (exp.24). Also, excess lactate in uterine vessels remained elevated (3.1 $\mathrm{mg} / 100 \mathrm{ml}$ ) in this experiment and in four other experiments. There was no excess lactate produced by the fetus in any of the experiments during recovery. The independence of the lactate concentrations in MV and UV during this period is shown in figure $2 D$.

\section{$p H$}

The changes in lactate concentration and $\mathrm{pCO}_{2}$ had a direct effect on the metabolic and respiratory components of $\mathrm{pH}$. The $\mathrm{pH}$ in UV during base line was lower than that in $\mathrm{MV}$ as the concentration of lactate and $\mathrm{pCO}_{2}$ were higher. Experiment 30 was the only exception. In this experiment, $\mathrm{pCO}_{2}$ and bicarbonate ion concentration were greater in $\mathrm{UV}$ than in $\mathrm{MV}$, whereas the concentration of lactate and hydrogen ion were lower. There appeared to be no exchange of these ions toward equilibrium across the placenta.

The potential effect of the lacticacidemia that occurred during hypoxia on the metabolic aspect of fetal $\mathrm{pH}$ was compensated by the effect on the respiratory component from maternal hyperventilation. As a result, $\mathrm{pH}$ showed no change during late hypoxia. The $\mathrm{V}$-A pH difference in uterine vessels did, however, widen significantly during late hypoxia $(P<0.01)$, while the umbilical $\mathrm{pH} \mathrm{V}$-A difference widened in six of the nine experiments. This observation could be explained by the results of the analysis of lactate and $\mathrm{CO}_{2}$ gradients presented above. The $\mathrm{pH} \mathrm{V}$-A differences during recovery were not significantly different from those found under base-line conditions.

\section{Discussion}

In sheep, the variability in lactate and pyruvate metabolism by the total uterus and fetus during acute nonhypoxemic conditions was similar to that observed in goats by HuckabeE et al. [6]. Higher concentrations of lactate and pyruvate were observed in the fetus than in the mother, and these observations are consistent with other reported data $[1,6]$. There appears to be no exchange of lactate or pyruvate between ewe and fetus. Further support for this contention was gained from the single experiment in which lactate concentration in the mother became markedly elevated, whereas in the fetus, lactate concentration remained within normal control limits. The independence of maternal-fetal concentrations that was noted for lactate was also found for the bicarbonate ion [2]. BLECHNER et al. [3] reported that the fetus showed no change in bicarbonate concentration when maternal bicarboin bicarbonate concentration when maternal bicarbonate concentration had decreased as a result of ammonium chloride infusion.

In experiments in which maternal arterial blood oxygen saturations were less than $87 \%$, Huckabee et al. concluded that excess lactate produced by the fetus was oxidized by the placenta, and therefore, no excess lactate was produced by the total uterus. Excess lactate production by the total uterus was noted in two experiments [7] in which the arterial oxygen saturation in the mother was extremely low. On the basis of these observations, Huckabee et al. proposed that when severe hypoxia occurred in both fetus and placenta excess lactate produced by the fetus diffused into the maternal circulation and was 'washed out'; analysis of our data confirmed this hypothesis.

The progressive reduction in oxygen tension to essentially anoxic values resulted in the accumulation of first pyruvate, and then lactate, in the umbilical and uterine circulations. The rise in concentration of lactate in UV was less than that in UA (positive UA minus UV difference in each experiment) so that lactate was lost from the umbilical circulation through the placenta at this time. The increase in concentration of lactate in MV was greater than the increase in MA (positive MV minus MA difference in each experiment). The direct relation between the concentration of lactate in UV to that in MV, which was noted during hypoxia, was not evident during either the recovery period or during base-line observations. The most plausible explanation for these observations would appear to be that lactate diffused from umbilical to uterine circulations, to which was added the lactate produced from anaerobic metabolism in the uterus. The diffusion of lactate across a membrane that appeared impermeable during acute nonhypoxemic con- 
ditions would involve alterations of the anatomical, electrochemical, or enzymatic characteristics of the membrane. A description of these changes remains for further investigation.

The consumption or production of lactate by the total uterine mass or fetus could be approximated by applying the observations on uterine and umbilical blood flow during hypoxia reported by DiLts et al. [4]. They noted an average fall in uterine blood flow of $30 \%$ during prolonged acute hypoxia (ewe respiring $6 \% \mathrm{O}_{2}$ ), and a fall in umbilical blood flow of $50 \%$. As the mean lactate V-A difference in uterine and umbilical vessels increased more than sevenfold in the present experiments, lactate production (flow times the $\mathrm{V}$-A difference, $\mathrm{mg} / \mathrm{kg} / \mathrm{min}$ ) should have increased significantly, even though flow had decreased below base-line values. Similarly, total uptake of glucose $(\mathrm{mg} / \mathrm{kg} / \mathrm{min})$ by the uterus should have increased significantly as the uterine glucose V-A difference increased twofold. However, the simultaneous production of glucose during hypoxia by mother and fetus, and utilization of glucose by anaerobic glycolysis complicated the analysis of changes in umbilical V-A differences. The significant narrowing of the umbilical V-A difference resulted from the reduction in the concentration of glucose in UV, possibly as a result of impaired glucose transport [13], and the rise in concentration of glucose in UA could have been a result of fetal glycogenolysis.

In both the uterine and umbilical placental circulations, a gradient in $\mathrm{pH}$ from artery to vein would alter the respective hemoglobin oxygen dissociation curves by the Bohr effect [8]. The V-A difference in $\mathrm{pH}$ during the base-line period resulted primarily from a difference in $\mathrm{pCO}_{2}$, as only minor differences existed in lactate and pyruvate concentration between the artery and vein. The loss of lactate from UA and gain of lactate in MV during hypoxia, however, widened the $\mathrm{V}$-A difference in $\mathrm{pH}$ in both the umbilical and uterine circulations. Additional oxygen was released from hemoglobin in the more acid MV as the dissociation curve was shifted to the right, while additional oxygen was bound to hemoglobin in the more alkaline UV as the oxygen dissociation curve of fetal blood was shifted to the left. Because the Bohr effect in whole blood is greater in the fetus than in the adult [12], the shift in the oxygen dissociation curve was of greater magnitude per unit of $\mathrm{pH}$ change in the fetus. A critical oxygen tension is approached, however, beyond which the effect is negligible. During recovery there was no significant loss of lactate on umbilical circulation through the placenta, the $\mathrm{pH}$ was significantly lower than base line in both UA and UV, but the $\mathrm{pH}$ difference between UA and UV was again regulated by differences in $\mathrm{pCO}_{2}$. The amount of oxygen bound to fetal hemoglobin and delivered to the fetus was diminished, however, due to the shift in the $\mathrm{O}_{2}$ dissociation curve to the right, even though the $\mathrm{pO}_{2}$ was equivalent to base-line values. Under these conditions, the fetus was relatively hypoxemic; correction of the metabolic acidosis depended upon the continued oxidation of lactate by the fetus.

\section{References and Notes}

1. Barker, J.N. and Britton, H.G.: Lactate and pyruvate metabolism in the fetal sheep. J.Physiol. 143: 50 (1958).

2. Barron, D.H. and Meschia, G.: The carbon dioxide concentration gradient between the fetal and maternal bloods of sheep and goats. Yale J. Biol. Med. 29: 480 (1957).

3. Blechner, J.N.; MESGiIA, G. and BARRoN, D. H. : A study of the acid-base balance of fetal sheep and goats. Quart J. exp. Physiol. 45: 60 (1960).

4. Dilts, P.V., Jr.; Brinkman, C.R. III; KirschBaum, T.H. and Assali, N.S.: Uterine and systemic hemodynamic interrelationships and their response to hypoxia. Amer. J. Obstet. Gynec. 103: 138 (1969).

5. Huckabee, W.E.: Relationships of pyruvate and lactate during anaerobic metabolism. I. Effects of infusion of pyruvate or glucose and of hyperventilation. J. clin. Invest. 37: 244 (1958).

6. Huckabee, W.E.; Metcalfe, J.; Prystowsky, H. and BARron, D.H.: Movements of lactate and pyruvate in pregnant uterus. Amer. J. Physiol. 202: 193 (1962).

7. Huckabee, W. E.; Metcalfe, J.; Prystowsky, H. and Barron, D.H.: Insufficiency of $\mathrm{O}_{2}$ supply to pregnant uterus. Amer. J. Physiol. 202: 198 (1962).

8. Mann, L.I. and Romnex, S. L.: The Bohr effect of fetal hemoglobin. Amer. J. Obstet. Gynec. 101: 520 (1968).

9. Mann, L. I.; Prichard, J. and Symmes, D.: EEG, EKG and acid-base observations during acute fetal hypoxia. Amer.J. Obstet. Gynec. (in press).

10. Meschia, G.; Cotter, J.R.; Breathnach, G.S. and Barron, D.H.: The hemoglobin, oxygen, carbon dioxide and hydrogen ion concentrations in the umbilical bloods of sheep and goats as sampled via indwelling plastic catheters. Quart.J. exp. Physiol. 50: 185 (1965).

11. Meschia, G.; Cotter, J.R.; Breathnach, C.S. and BARron, D.H.: The diffusibility of oxygen across the sheep placenta. Quart.J.exp. Physiol. 50: 466 (1965).

12. Schruefer, J.J.P.; Heller, C.J.; Battaglia, F.C. and Hellegers, A.E.: Independence of whole blood and hemoglobin solution oxygen dis- 
sociation curves from hemoglobin type. Nature, Lond. 196: 550 (1962).

13. Wrodas, W.F.: Transport mechanisms in the fetus. Brit.med. Bull. 17: 107 (1961).

14. Biochemical-test combinations, G.F. Boehringer \& Sons, Mannheim, Germany.

15. Model 123-S, 125-B, 127, and Instrumentation Laboratory, Inc., Lexington, MA 02173.

16. The participation and cooperation in these experiments of Dr. J. Prichard and Dr. D. Symmes of the Behavioral Biology Branch, NICHD, and Dr.
S. CobB and Mr. L. Stuart of the Poolesville NIH Animal Farm was deeply appreciated. Thanks are due to Dr. W. Glinsmann of the Laboratory of Biomedical Sciences, NICHD for his critical review of the manuscript.

17. This report was prepared with the technical assistance of Mrs. Lynn Hern.

18. Requests for reprints should be addressed to: LEon MANN, M.D., The New York Hospital, 525 East 68th Street, New York, NY 10021 (USA). 19. Accepted for publication August 22, 1969. 